\title{
Exploration on the Application of Modern Apprenticeship in Mechanical and Electrical Integration Technology Specialty Vocational College
}

\begin{abstract}
Xiaoli $\mathrm{Hu}^{1}$
${ }^{I}$ Jiangxi Vocational Technical College Of Industry \& Trade, Jiangxi, Nanchang,330038

739960103@qq.com

ABSTRACT

Mechatronics technology is a comprehensive system technology, combined with automatic control, servo drive technology, the technology for students' professional application skills requirements are very high, so it is urgent to find a teaching mode to help students to carry out professional skills training. This paper analyzes the characteristics and connotation of modern apprenticeship teaching mode from the perspective of mechatronics technology major, and puts forward the corresponding upgrading ways through the discussion of the problems existing in the current implementation process of the mode in China.
\end{abstract}

Keywords: mechatronics technology, modern apprenticeship, practice

\section{机电一体化技术专业中关于现代学徒制的应用探索}

\author{
胡晓莉 1
}

\section{${ }^{1}$ 江西工业贸易职业技术学院 江西 南昌 330103 \\ 739960103@qq.com}

摘要:

机电一体化技术是一门综合性的系统技术，结合了自动控制、伺服传动等技术，该技术对于学生的专业应用技 能要求十分的高, 所以急需找到一个能够帮助学生进行专业技能培训的教学模式进行教学。本文以机电一体化 技术专业为切入点, 分析现代学徒教学模式的特点和内涵, 在通过对当前该模式在我国实施过程中存在的问题 探讨，提出相应的升级途径。

关键词: 机电一体化技术; 现代学徒制; 实践

\section{1.引言}

高职院校是我国教育体系中重要的一部分, 建立 的目的在于为国家培养高新技术型人才，院校专业重 点在应用技术教学上。对于机电一体化技术专业学生 来说, 掌握专业的应用技术能力是至关重要的, 比如 处于生产制造线, 则必须掌握好机器设备的组装、修 理等。对于学生来说, 如果只靠学校书本身的理论知 识, 没有训练动手的实践体验, 是没有办法在这个专 业上做到学有所成的。因此, 为了让学生将理论与实 践相结合, 形成了一种名为现代学徒制的教学模式。 通过学校与企业合作教学的方式, 学生在学校学习理 论知识后, 进入企业在师傅的带领下进行实践学习。 实施现代学徒教学模式对我国的人才培养具有很大
的意义, 有助于将学生教育成知识应用型人才。

\section{2. 高职机电一体化技术专业采用现代学徒制 教学模式的特点}

如今的现代化学徒教学模式是在传统上, 结合现 代教育特点进行改良的新型教育模式, 更加符合当代 社会发展的要求。我国职业院校目前正广泛的运用现 代学徒模式实行教学, 在我国该模式成为了很受欢迎 的一种教育模式。该教学模式起源于以德国为主的西 方国家，至今，德国依然被标记为该制度的范本。德 国将职业教育设置为职工们的终身教育, 并且建立了 专业的法律文件对其进行保护，德国学徒制的教育流 程十分的专业且完善, 从培训到上岗, 再次培训、再 
次上岗, 充分地保证学生真正的将专业理论和操作学 会。职业教育在德国有这么好的效果, 也离不开其实 行的“双元教育体系”, 该体系规定了在给学生实施职 业教学工作的时候, 学校和企业必须要互相配合着进 行教学指导。在现在师徒教学模式上, 澳大利亚也有 很大的研究成果, 甚至隐隐超过德国, 关键在于其提 出的“新型学徒制”将市场需求纳入到了教学体系当 中, 政府根据市场情况为方向, 将学生数量、课程数 量以及教育成果三者作为评判标准, 进行教育经费拨 款。不难看出, 德国和澳大利亚在职业教育上这么好 的成绩，离不开国家的支撑。

随着我国社会的不断进步, 经济结构也发生着很 大的转变, 社会所需人才随着时代的前进也有所变化, 所以为了培养出符合当代国情所需的人才, 设置一种 有组织性并且教育流程完善的教学体系至关重要, 而 现代学徒制正好可以满足这个要求。对于我过来说, 照搬他国的教学模式肯定是行不通的, 每个国家都有 其独特的地方, 所以, 想要在我国顺利的实行该教学 模式, 还得依据我国国情将其进行调整, 最终形成一 套完善的教学体系。学徒制最主要的是能够将动手能 力融入专业教学当中, 依据社会工作实际所需, 进行 轮换式的培训。作为老师, 必须将实际工作加入到理 论教育之中, 让学生的教学在实践中实施, 通过双师 教学。再加上项目经理性的技术指导保证学生学到真 正的能力。要想学生能够进入企业进行实践学习, 则 必须将学生的在校学习时间和公司培训时间协调, 严 格根据公司员工准则对学生表现进行评估, 保证在公 司进行实践学习期间了解企业运营模式。

\section{3.现代学徒制教育模式的内涵与现代学徒制 的教学过程}

\section{1 现代学徒制教育模式的内涵}

现代学徒教学模式将学校和企业两者链接起来, 相比于传统的教学模式, 现代的模式更加的完整而且 更加的细致化, 学生能够学到系统的知识和专业的培 训。在现代学徒模式下, 把学习时间划分成三份, 三 分之一的时间在学校学习专业所需的理论, 剩下三分 之二的时间在企业跟着师傅学习实际工作所需的能 力。在理论和实践的协调配合下, 学生能够准确的掌 握好专业技能。在校园学习阶段通过系统的培训, 就 能培养出社会工作所需的团队意识, 形成优秀的自由 素质, 为将来步入社会做好准备。关键的是, 企业和 学校结合的模式非常的人性化, 在企业进行学习时, 不会像学生收取任何的培训费用, 甚至会给学生发放 工资补贴。现代学徒教学已经成为了我国进行职业教 育的重要模式, 该模式注重社会的实际发展情况, 重 点在于让学生在真正的工作氛围下进行学习。

\section{2 现代学徒教学模式流程}

\section{2 .1 使用优质教材, 选拔高素质双师教学团队}

高职院校在进行生源选拔时, 必须严格按照规章 制度, 从学习成绩和学习态度两个维度上, 录取不仅 基础知识牢固, 而且学习态度端正、有理想有抱负的 学生。在学校学习的初级阶段, 学习的重点还是在基 础的理论知识学习上, 教学所用的教材不能只是理论 知识的堆砌, 而应是与实际运用牢牢结合, 内容涵盖 充足且易于理解。而作为教育工作者, 老师的教学讲 解也不能只流于课本表面, 在设计课程内容时, 要考 虑到学生未来社会实践时的需求, 结合实时案例进行 讲解, 引导学生深入的思考与学习。所以, 师资力量 在教学之中至关重要, 组建教师团队时, 必须确保老 师有能力配合好学校和企业双方之间的关系, 并且能 够照顾好学生的情绪, 帮助学生适应身份转变。

\section{2 .2 严格选择校企合作试点企业}

在进行合作教学的企业选择时, 学校必须担负起 责任严格把控, 把为学生营造精良的实践学习条件为 主根本目的, 不仅要看到公司在生产技术和设备上的 硬实力, 还要注意公司企业文化和人才培养上的软实 力, 选取最适合学生教学的企业。为保证学生在企业 学习期间接受到优质的培训, 保证学生的权利, 学校 和企业双方必须签订相关的合作契约, 确定双方应履 行的责任和享有的权利。

\subsection{3 校企合作开发教学资源与考核方案}

为了将学校理论学习与企业实践学习紧密的连 接起来, 双方都要组件专业的项目实施团队开展工作, 教学方案必须通过双方共同交流探讨, 课程开展的每 个阶段都要互相进行反馈交流。企业将学生实践期间 的表现成果反馈给学校, 并提出相关的提升策略, 不 断的根据实际情况调整应的理论知识和动手技能培 训。双方在进行交流的一项重要内容就是对目前的教 材进行改编, 比如在《机械制造技术》和《数控技术》 等教材之中融入现代的生产技术, 形成合适企业和学 习教学的系统化教学模式。在学生表现考核上, 因多 维度进行评估, 不仅要考虑到在学校学习期间对理论 知识的掌握程度, 在企业表现期间实际动手能力, 还 要注重学生的思想道德表现和职业素质。

\section{4.现代学徒制在实践中的难题}

\section{1 教学模式与评估制度不完整}

目前阶段，我国大部分高职院校的实践培训依旧 是在学校进行, 教学的重点在教材的讲解上, 在理论 知识学习上建立了完善的教学流程, 而忽略了学生将 来工作实际所需的能力。教学内容有很大的空白, 没 有注意到与企业进行交流合作, 实践教学不足, 以至 
于学生在校学习的专业知识与企业职工所需的专业 技能存在很大的偏离。虽然学生在学校也进行了一定 的实践操作教学, 但这都只是学校根据企业实际工作 的状况所设计的一部分内容, 学生难以有学习到完整 的工程技能培训机会。在进行学生表现评估时, 评估 内容也是以在校理论知识学习成果为主, 企业培训表 现并没有深入的进行考核, 评估成绩无法说明学生是 否符合企业所需。

\section{2 对教学模式存在误解}

目前，在我国大部分人的价值观里，蓝领工人薪 酬福利以及工作环境相对而言比较糟糕, 不是一份 “体面”的职业, 没有得到社会的认可。这使得很多学 生不愿意考虑现代学徒制的教学模式, 学校在进行生 源招聘时也面临着很大的挑战。很多人认为企业和学 校合作只是为了找廉价劳动力, 对于学生职业发展毫 无用处。对于学校而言, 只是将实践教学比重拉大, 而为了让教学不偏离社会实际所需, 恰好采用了现代 师徒教学模式这一种简洁高效的教学模式。

\section{3 缺乏专业的教学团队}

现代师徒教学模式采用的是双师教学的模式, 需 要学校老师和企业师傅的互相配合。学校老师的理论 知识比较充分, 而实际操作能力较差, 相反, 师傅在 工作岗位实践了多年, 实际操作技能成熟, 但缺乏专 业的教学能力, 在教学的过程之中, 双方很大概率会 发生矛盾争执, 这就需要提升双方的教师团队。

\section{4 重视理论授课, 轻视实践教学}

现代学徒制在实践中的难题，除了上述三种以外, 还存在着重视理论轻视实践教学的情况。机电一体化 传统的教学方式主要是指教师在讲台上利用一块黑 板和教师手中的教材对学生授课。但是就机电一体化 专业教学来说, 机电一体化技术是十分注重实践教学 的, 教材中的知识多为原理和概念, 教学内容复杂多 变, 从而导致了学生在教师的教学中难以真正的了解 到机电一体化专业中的技术重点, 使学生在实际操作 容易出现偏差。再者企业对于机电一体化技术的操作 能力比学校的要求更高, 从而会增加学生往后的日常 工作的难度, 并且职业院校也难以满足社会对于专业 化人才的需求量。

\section{5.现代学徒制难题的解决措施}

\section{1 构建完善的教育模式和考核体系}

教学的目的在于培养出真正符合社会经济结构 所需要的人才, 所以, 在进行课程体系的规划时, 不 仅要注重学生专业理论知识和实际操作能力, 还要注 重培养学生的专业素质, 要将对学生创新创业意识的 培养加入到教学内容之中。根据当今企业的实际情况,
完善教学内容和考核体系, 让学生在校期间掌握专业 理论知识和专业企业技能。考核方式因分为多个模块, 多方面评估综合考虑, 明确规定考核的标准, 公平公 正的进行评估。

\section{2 完善教学管理方案}

学校和企业要根据市场情况随时进行交流探讨, 建立合理的反馈机制, 将学生在校以及在企业学习期 间的表现反馈给对方, 保证双方教学不脱节。双方必 须对学生的培训计划探讨出明确的细节, 以便于学校 可以根据企业的实际情况, 将教学内容进行修改。企 业在进行培训时, 可设立奖励制度, 激励学生学习。 在机电一体化技术专业, 对于教学的目标要明确, 通 过学校和企业进行教学模式探讨后, 还应该定期的举 办各种相关的分享会, 邀请学术学者和企业大咖分享 自己的见解等。

\section{3 加强师资团队力量}

学校和企业双方应该考虑到培训的特殊性, 老师 和师傅都是带有双重身份的, 在师资团队的选拔时, 不仅要注重教师的专业能力, 还要注重教师的教学能 力, 要能够注意到学生的心理问题, 并且有良好的沟 通协调能力, 对于双方的责任必须明确的表明在契约 之中。保证双方的合作能够顺利的进行。

\section{6. 结论:}

目前阶段, 我国经济结构高速转变, 产业不断升 级, 这是我国的机遇也是挑战。从制造大国到制造强 国, 当前所需的人才与学校所培养出的学生之间存在 着很大的差距, 通过与企业的合作教学模式, 是缩短 这一差距的有效办法, 能够有效地推动我国人才发展 建设。现代学徒制的实行离不开学校和企业的相互配 合, 不断地完善教学内容和评估模式, 要想提升公众 群体对蓝领的认可, 转变师徒制在我国的地位, 离不 开国家的支持。只有依靠多方的共同协调努力才能过 促进该教学模式的长久发展。

\section{REFERENCES}

[1] Hu Jinde, Fu Xiaojun, Hu Huawen. Curriculum system reform and practice of Mechatronics Technology Specialty in Higher Vocational Colleges Based on modern apprenticeship system [J]. Journal of Xiangyang Polytechnic, 2018, 17 (04): 34-37

[2] Li Guifu. Theory and practice of modern apprenticeship in Higher Vocational Education in Jiangsu Province: a case study of logistics management major in Yancheng Polytechnic [J]. Scientific consulting, 2015, 0 (45): 150-152 
[3] Liu Qinglun. Exploration and practice of "modern apprenticeship" in mechatronics specialty [J]. Modern manufacturing technology and equipment, 2017 (01): 184-185

[4] Li Chuanwei, Wang Yanni, Jiang Yi. Research on teaching diagnosis and improvement of modern apprenticeship pilot project -- Taking provincial modern apprenticeship Mechatronics pilot specialty as an example [J]. Journal of Tianjin Radio and TV University, 2016, 20 (03): 54-59

[5] Zhu Jun. practical research on the talent training mode of "work study six integration" from the perspective of modern apprenticeship -- Taking Wuxi electromechanical higher vocational and technical school as an example [J]. Vocational education communication, 2014, 0 (32): 9-11

[6] $\mathrm{Xu}$ Yueqing. Exploration and Practice on the innovation of Five-year Higher Vocational Talents Training Mode -- Taking Wuxi electromechanical higher vocational and technical school as an example [J]. Going abroad and Employment: employment education, 2011 (20): 51-52

[7] Liu Qiaozhi, Xu Li. Research and practice of higher vocational talents training mode based on Modern Apprenticeship -- taking food nutrition and Testing Specialty as an example [J]. Agricultural products processing (2), 2015, 0 (4): 81-84

[8] Wang Xiaozhong. Research and practice of modern apprenticeship talent training mode -- Taking Wuxi electromechanical higher vocational and technical school as an example [J]. New curriculum: teacher, 2014, 0 (11): 23-25

[9] Kang Xiaomeng, Shen Fuzhi. Thinking and strategy of practicing modern apprenticeship in petrochemical specialty of Higher Vocational Education -- Taking Yangzhou Polytechnic as an example [J]. Journal of Jilin Institute of chemical technology, 2016, 33 (10): 51-54

[10] Ye Ke, Lu Jingbing, Zhu Gang, Wang Fang. Innovating practice mode and promoting modern apprenticeship -- Taking Automobile Inspection and maintenance technology major of Beijing Agricultural Vocational College as an example [J]. Journal of Beijing Agricultural Vocational College, 2016, 30 (6): 67-72

[11] Zhang Qingling. Research and practice of enterprise curriculum construction under the background of modern apprenticeship -- Taking the course of "urban rail vehicle experiment and driving" of urban rail transit specialty of Changchun Polytechnic as an example [J]. Journal of Nanning Polytechnic, 2017, 22 (1): 35-38
[12] song qunling, Teng Yu, Li Yingjuan, Zhang Wenli, Cai Chuanxiong. Discussion on "order apprenticeship" talent training mode of Metallurgical Technology Specialty in Higher Vocational Colleges [J]. China's off campus education: late, 2017,0 (4): 154-155

[13] Zhang Guiyuan. Research on curriculum standard formulation of modern apprenticeship enterprise - Taking the course of "urban rail transit control post practice" as an example [J]. University: teaching and education, 2020 (11): 45-47

[14] Wang Shi'an. Research on studio based modern apprenticeship in Higher Vocational Education -taking computer simulation major of Guangzhou Polytechnic as an example [J]. Vocational Education Forum, 2013 (27): 14-16

[15] Yan Xueqing, Chen Xiaohua. Logistics personnel training and social adaptation in Higher Vocational Colleges from the perspective of modern apprenticeship -- Taking vocational education of new generation migrant workers in Dongguan, Guangzhou and Zhongshan as examples [J]. Logistics technology, 2015, 38 (4): 34-36

[16] Zhao Yumei, Zhang Ran. Practical research on Modern Apprenticeship talent training mode of automobile repair major in Higher Vocational Colleges -- Taking Tangshan Institute of technology as an example [J]. Industrial technology and vocational education, 2016, 14 (2): 24-25 